\title{
THE CASE FOR GOVERNMENT BY ARTIFICIAL INTELLIGENCE
}

by

\author{
STEVEN JAMES BARTLETT \\ Visiting Scholar in Psychology and Philosophy, Willamette University \\ and \\ Senior Research Professor, Oregon State University \\ e-mail: sbartlet [at] willamette [dot] edu
}

KEYWORDS: government by artificial intelligence, theory of government, human cognitive limitations, human psychological limitations

The author has chosen to issue this essay as a free open access publication under the terms of the Creative Commons Attribution-NonCommercial-NoDerivs license, which allows anyone to distribute this work without changes to its content, provided that both the author and the original URL from which this work was obtained are mentioned, that the contents of this work are not used for commercial purposes or profit, and that this work will not be used without the author's or his executor's permission in derivative works (i.e., you may not alter, transform, or build upon this work without such permission). The full legal statement of this license may be found at

http://creativecommons.org/licenses/by-nc-nd/4.0/legalcode

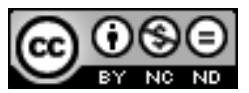

(C) Steven James Bartlett, 2016 


\title{
THE CASE FOR GOVERNMENT BY ARTIFICIAL INTELLIGENCE
}

\author{
STEVEN JAMES BARTLETT
}

The larger the mob, the harder the test. In small areas, before small electorates, a first-rate man occasionally fights his way through, carrying even the mob with him by force of his personality. But when the field is nationwide, and the fight must be waged chiefly at second and third hand, and the force of personality cannot so readily make itself felt, then all the odds are on the man who is, intrinsically, the most devious and mediocre - the man who can most easily adeptly disperse the notion that his mind is a virtual vacuum.

The Presidency tends, year by year, to go to such men. As democracy is perfected, the office represents, more and more closely, the inner soul of the people. We move toward a lofty ideal. On some great and glorious day the plain folks of the land will reach their heart's desire at last, and the White House will be adorned by a downright moron.

- H. L. Mencken, Baltimore Evening Sun, July 26, 1920

$\mathrm{N}$ ot to smile, frown, grimace, or cringe in response to the subject of this essay may require one part freedom from prejudgment, one part imagination that combines humility about our species, and a liberal dash of broadmindedness of uncommon amplitude.

The human record of self-governance is surely dismal. Despair over the capacity and the ability of human beings to govern themselves without conflict and without incompetent decision-making is more than strongly justified by the species' history.

This is the starting point of the discussion that follows, a starting point that is taken for granted as the unquestionable, morethan-well-established truth about human beings throughout their long and spotty record of governing themselves. A host of compelling reasons to accept this truth can be given, but that will not be the purpose here. Instead, we'll review and weigh certain of the 
main human limitations that obstruct intelligent, reasonable, efficient, and effective good government, limitations that artificial intelligence does not have.

'Good government' is of course a value-laden phrase, open to undeniably never-ending debate. That debate, too, will be set to one side. The purpose here is instead specific: to direct attention to human fallibilities, frailties, and intrinsic human handicaps that stand in the way of intelligent, reasonable, efficient, and effective government, all of which criteria are implied and are fundamental in any enlightened view of what the 'good' in 'good government' means or ought to mean. ${ }^{1}$

The human fallibilities, frailties, and intrinsic human handicaps that have been responsible for disabling, undermining, wrecking, and destroying human societies, both from within and from without, are legion, but a select few can easily be identified as having played major roles in human self-destructive history. Here is a short list:

Human cognitive limitations, among them:

Limited intelligence

- Limited individual memory capacities, further handicapped by the need of each generation to learn the same things all over again

Limited abilities in sorting, organizing, and managing

\footnotetext{
${ }^{1}$ A note for philosophically inclined readers: Again, no attempt will be made to defend this second basic premise. If we've learned anything that can be transposed from major mathematical discoveries of the last century, it is that there is no absolute justification that can be given for the acceptance of any set of most basic axioms. As Belgian logician Jean Ladrière expressed this, "The absolute justification of an axiomatic system should very likely be considered, in its most general sense, as an unrealizable task (and perhaps one that is devoid of meaning)." (" $[\mathrm{L}]$ a justification absolue d'un système axiomatique doit très probablement être considérée, en tout cas en général, comme une tâche irréalisable (et peut-être dépourvue de sens).") Préface by Ladrière in Isaye, Gaston (1987). L'Affirmation de l'être et les sciences positives. Paris: Éditions Lethielleux, p. 16.
} 


\section{information effectively}

- Inabilities to understand and to take comprehensively into account what, for human beings, is mentally overwhelming complex information

- Limited problem-solving and decision-making abilities

- The propensity for human error, involving errors in factual understanding, errors in thinking, and errors in judgment

Human psychological limitations, among them:

- Individual and group vested interests, ranging from ideological, religious, to acquisitive-all varieties of territorialism and self-promotion, coupled with aggression directed at suppressing whatever is perceived to challenge these

- Domination of the human species by emotional responses under poor or non-existent rational executive control

- Species arrogance that stands in the way of accurate self-appraisals, and last

- Political obsession, typically an expression, as we will see, of specific destructive human dispositions

If we are able and willing to engage in truthful self-evaluation about our species, there is no reason why all of these limitations cannot in time be overcome. However, honest human selfappraisal has proved, for millennia, to be elusive and to be stubbornly resisted.

Here, we look at the case that can be made for a potentially promising and direct way to overcome our species' persisting limitations - through the technical means that evolving artificial intelligence can be expected to offer. Those means conceivably can make intelligent, reasonable, efficient, and effective human government plausible.

The case for government by artificial intelligence rests on an understanding of the human limitations listed above. Let us briefly 
examine a few of these.

A rule-of-thumb that applies to the normal human cognitive capacity which permits people to keep a very small number of things in mind at one time has come to be known as Miller's $7 \pm 2$ Principle. Few people can, even immediately afterwards, recall more than 9 unrelated numbers or names that are read to them; most people fall in the 5 to 9 range. - This, to be sure, is a selfevidently very elementary level of mental attainment, dwarfed into complete insignificance by even the most rudimentary computers.

Why is this ability - to keep a group of things in mind and recall them-important, specifically when, as here, governing a nation is at issue? Is a world that at present consists of some 196 different countries, each with highly varied social, economic, political, and religious conditions and commitments, so simple, involving so few factors that need to be weighed, balanced, and foreseen, that this world of complexity can be effectively understood, comprehended as an intertwined whole, and managed by beings who are only able to keep fewer than a mere dozen things in mind at once, and then recall them? To raise this question in this way is to point to its clear and humbling negative answer. And Miller's limiting $7 \pm$ 2 Principle relates to only one small part of the iceberg of cognitive abilities that competent governance presupposes.

In the United States, to take the example of a single country, there are at present no existing qualifications to be President, other than simply to be a native-born citizen. In a country where, to be entrusted and licensed to drive even a car or school bus, to fly a passenger plane, or to provide medical or legal service, one has to pass basic exams intended to verify competence, there are no relevant qualification requirements whatever to be a U.S. president. Civil service jobs require passing some basic tests that give a rough estimate of an individual's basic intelligence and problem-solving ability. Should we not also insist that presidential candidates meet fundamental, self-evident prerequisites or standards of competency-at the very least among them, better-than-a-modicum of apparent intelligence? (Emotional maturity, psychological stability, impulse control, plus other obvious qualifications of course should 
be thrown into the mix of essential prerequisites-including a formal education leading to thorough knowledge of the history, laws and public needs of the candidate's own country, law, and public needs, a solid knowledge of international affairs, basic training in economics and the psychology of diplomacy, etc., and most importantly, freedom from the governance-blocking human handicaps that we'll discuss in what follows. It is unlikely that many-if anypast U.S. presidents would meet these requirements.)

Since nearly all people are convinced that intelligence in a leader is essential to his or her capacity to govern, it is interesting to note that the Lovenstein Institute, in Scranton, Pennsylvania, a think tank staffed by psychiatrists, sociologists, historians, and human behavioral scientists, has, since 1973, published its findings relating to the intelligence of former U.S. presidents. Over the past half century, from F. D. Roosevelt to G. W. Bush, the IQs of a dozen presidents have been rated based on such criteria as their writings (written by themselves - that is, without outside help), their individual abilities to speak clearly and articulately (scored using the Swanson/Crain system of intelligence ranking), depth of sentence structure, and voice stress confidence analysis. Here are a few of the Institute's results (their ratings are touted by the Institute as accurate within 5 IQ points, but even so its estimates may tend to err on the side of rather excessive IQ generosity):

In order of increasing IQ:

$\begin{array}{ll}91 & \text { George Walker Bush [R] } \\ 98 & \text { George Herbert Walker Bush [R] } \\ 105 & \text { Ronald Wilson Reagan [R] } \\ 121 & \text { Gerald R. Ford [R] } \\ 122 & \text { Dwight David Eisenhower [R] } \\ 126 & \text { Lyndon Baines Johnson [D] } \\ 132 & \text { Harry S Truman [D] } \\ 147 & \text { Franklin Delano Roosevelt [D] } \\ 155 & \text { Richard Milhouse Nixon [R] } \\ 174 & \text { John Fitzgerald Kennedy [D] } \\ 175 & \text { James Earle Carter [D] } \\ 182 & \text { William Jefferson Clinton [D] }\end{array}$


The six Republican presidents of the past 50 years possessed an average estimated IQ of 115.5, or slightly higher than the average human IQ of 100; President Nixon had the highest of Republicans, an IQ of 155. We see that President George W. Bush came in at the bottom of all the Republicans with an IQ of only 91. (His low IQ was attributed to his challenged command of the English language as revealed in his public speaking, his limited vocabulary (his active vocabulary of only 6,500 words did not compare well with an average working vocabulary of 11,000 words for other presidents), his lack of scholarly achievement (other than having received an MBA, a perhaps questionable "scholarly achievement"), and the non-existence of any written work authored by him (in the form of published books or white papers) that could be evaluated in terms of intellectual attainment.)

The six listed Democratic presidents had a substantially higher average IQ of 156; President Clinton possessed the highest IQ, 182. President Lyndon B. Johnson was ranked the lowest of the Democrats, with an IQ of $126 .^{2}$

Although these findings, which comprise only very approximate estimates, may be interesting in their own right, what do they tell us that bears on our subject?

For one thing, it's clear that presidential intelligence must be a sought-after ability in a country's leaders-at least presidential intelligence is sufficiently valued for a think tank to have engaged in its study over a period of more than three decades. On the one hand, the findings of the study should make us wonder at the risks incurred by a nation when (or if) the intelligence of some of its presidents has been as low as the above list shows. On the other hand, we might feel some encouragement that the IQs of a good number of past presidents have been rated so highly. And of course some people would no doubt wonder whether IQs really are

\footnotetext{
${ }^{2}$ Bear in mind that these are the Lovenstein Institute's IQ estimates based on the application of specific and limited criteria. No president other than Carter has disclosed his actually tested IQ (176).
} 
all that important in a U.S. president—after all, all presidents depend (we hope) on others who know more than they do, to give them "expert advice."

What we need in this discussion is a broadened perspective, which artificial intelligence provides. Already, the highly valued, elite intellectual skills cultivated by human chess and go champions have succumbed to the surpassing abilities and speed of machine intelligence. IBM's Deep Blue defeat of chess champion Garry Kasparov is already approaching its twentieth anniversary, and although a good deal of AI progress has happened since then, the evolution of genuinely powerful AI has really only barely begun. Even so, and just in comparison with the arithmetical abilities of even discount store $\$ 1$ hand calculators, most of us have already humbly ceded the game and set to silicon circuits. (And we are not ashamed to do this.)

It is not a matter of science fiction and pure fantasy to recognize that limited human IQs, even those perhaps unreliably estimated to be in the over-150 range, really do not mean very much when it comes to handling complex and extreme data-laden information, the need to sort out most salient factors, then to devise solutions to problems that explicitly take into account the multitude of competing national and international political, social, health, economic, environmental, ideological, religious, and other variables relating to some 200 different countries, multiplied by the many other categories of essential human interests and values, and then-once these preliminary tasks have been accomplished-to predict, weigh, and wisely choose among the statistically probable consequences of contemplated decisions if they were to be implemented on a national or global level.

This is a level of complexity and multi-dimensionality that, in comparison, makes chess or go child's play. Machines already have left humans in the dust in a great many respects. They have quickly excelled as mere calculating machines, but beyond such demanding games as chess and go, already we have become utterly dependent upon the AI control of the most advanced aircraft and space vehicles, which simply cannot be controlled without computer assis- 
tance. Applications of AI are rapidly now surpassing human abilities and speed in medical diagnosis; legal, technical, scholarly, and computational mathematics research; in library science and general database management; and very soon even when it comes to safe personal vehicle control.

This increasing, outright, and utter human dependency upon what are at present only rudimentary realizations of potential AI capabilities has come about quietly, with scarcely a murmur of serious public concern. It is universally admitted that surrendering human control to calculating machines is completely unavoidable when it comes to world stock markets, handling the exploding human population's financial transactions, finding one's way to an unknown address by GPS, local and international policing, connecting with one's friends, family, and social network through the Internet and cell phones, guiding interplanetary missions, securing our homes and businesses against burglary and cyberattack, and now even driving our own vehicles. Surrendering control to AI happens primarily because it almost entirely saves us from ourselves, that is, from our error-prone, cognitively limited, distraction-prone mental processing and decision-making, and it saves us from the no longer acceptable slowness and fallibility of human thinking.

The third major cause of death in the United States at the present time is due to human medical error-the prescribing of the wrong treatments and of medications in the wrong doses, and errors occurring during surgery. Much of human error is likely to become avoidable, by increasingly reliable developments in artificial intelligence, as we are saved from ourselves in an increasing number of areas of human life and endeavor. Human error and consequent poor human judgment are ubiquitous, playing obvious roles in human governmental mismanagement, and paving the way for continued national crises and wars between nations.

Human beings have so far not shown reluctance to give way before many of these advances in the growing set of still-basic AI abilities, and many people have begun to see the light, even to the extent of accepting that their habitual and predictable vehicle acci- 
dent rates will very likely go down once the control of their individual vehicles is removed from dangerous human control. Even so, some people, also predictably, have begun express stubborn human recalcitrance and pride that must be overcome when-not if-direct human control in driving their cherished vehicles is relinquished to machines.

Autonomous vehicle control provides an encapsulation in miniature of some of the issues facing government by artificial intelligence; in both, people are faced by the need to surrender their control to machine intelligence.

Autonomous vehicle control itself is but a small step for man; but government by AI would indeed be a large step for mankind. Government by artificial intelligence will have an undeniably steep mountain of ingrained habit and human pride to climb. But the motivation to attempt that climb receives a good deal of impetus when we look at the second major category of human limitation, that of human psychological limitation.

In two books, ${ }^{3}$ the author has studied a large group of shortcomings found in the majority of psychological normal people. Some of these shortcomings-when circumstances are right (as they too often are) - so clearly are destructive to others, and often to the individuals themselves, as to merit the non-metaphorical application to them of the diagnostic label "pathologies." As a species, we have long regarded "psychological normality" to be a standard of good mental health. To challenge this presumption is to challenge both a human mindset that has grown to be so comfortably deep-seated as to be impervious to critical thinking, as well as the man-in-the-street's supreme faith in "common sense" and in the glowing mental health and stability of "regular people."

Unfortunately, the man-in-the-street has often been wrong; what he believes is what it satisfies him to believe in. As H. L.

\footnotetext{
${ }^{3}$ Bartlett, Steven James (2005), The Pathology of Man: A Study of Human Evil. Springfield, IL: Charles C. Thomas; and Bartlett, Steven James (2011), Normality Does Not Equal Mental Health: The Need to Look. Elsewhere for Standards of Good Psychological Health. Santa Barbara, CA: Praeger.
} 
Mencken observed, “The average man does not get pleasure out of an idea because he thinks it is true; he thinks it is true because he gets pleasure out of it." 4

Psychologically normal human beings, taken as a group, share dispositions to think and behave-again when circumstances are right - in ways that we know result in aggression, destructiveness, and needless suffering. "Pathologies of normality" are a new category of psychological dysfunction, a category that mainstream DSMvested psychiatry and clinical psychology have yet to recognize. But these pathologies are very real, and the evidence for them is overwhelming for any who are willing to look at and comprehend the data.

The short list of human psychological limitations given at the beginning of this essay identify human traits and dispositions that express some of the destructive manifestations of pathologies of normality. They include beliefs that have their roots in political or religious ideology, beliefs that set individuals and their groups against other individuals and their groups, and nations against nations. In the conflicted and typically violent interactions that result, the clash between mutually incompatible systems of belief elicits emotional responses that are seldom adequately managed by what we have come to call "rational executive control." The results of these conflicts are frequently destructive on an extreme scale.

The last entry on the list of psychological limitations, that of "political obsession," may puzzle some readers. As the author has shown elsewhere, ${ }^{5}$ psychologically normal people typically share dispositions that predispose them to identify themselves with a favored group, and to conflict with other groups toward which they therefore feel enmity. These dispositions include:

an affiliative need to feel part of a group, from which individuals gain a larger sense of personal identity and importance than they would otherwise have;

\footnotetext{
${ }^{4}$ Mencken, H. L. (1918), Damn. New York: Alfred A. Knopf, p. 123.

5 See note 3 .
} 
a sense of identity derived from herd membership that provides them with a set of beliefs and a premanufactured outlook - a set of values and guidelines for their thinking and behavior that they have only to accept and have no need to question-to which they readily wish to conform;

- a love of politics that offers people a distraction, a source of entertainment and diversion from their ordinary lives, and a focus of interest beyond themselves, which together make political obsession psychologically rewarding and emotionally stimulating while at the same time offering people causes that engage and absorb their attention and passions;

- the emotional attraction of the contest-nature of elections, which possess a strong and addictive lure for people who enjoy and are gratified by interpersonal conflict, by the often emotionally heated exchanges and debates between contestants, and by the competitive sports-like game atmosphere that many elections generate; and, last,

- in a democracy, a readily satisfied hungry belief on the part of the members of the voting electorate that their personal opinions truly matter and will make a meaningful difference to the exciting outcome.

These inherently psychological traits, shared by the psychologically normal majority, have a dark side. The same traits-identity derived from group membership, the attraction of a predetermined group dogma, the stimulus and gratifications resulting from the group's commitments, enjoyment of the contestatmosphere of conflict, and the feeling that one's place in the group makes a real difference-these are the seamless expressions of human dispositions that are responsible for much human aggression, destructiveness, and widespread suffering. When people 
elevate on a pedestal their own preferred group and its beliefs, typically in antagonistic opposition to those of competing groups, human divisions are drawn, and derision and dehumanization of nonmembers set in. When psychologically normal people enjoy conflict, finding it exciting and a source of lived meaning as they are known to do during uprisings, revolutions, and wars, the fever of conflict clouds their consciousness, and the emotional urge to suppress, defeat, or destroy opposing groups takes over rational control.

Political obsession is, in short, not the innocent source of pleasure that most take it to be, and the psychological needs it gratifies will be very hard to give up if a time comes when government by dispassionate artificial intelligence is openly considered.

When autonomous vehicles become commonplace, incidents of road rage will predictably decline, thanks to vehicle control having been taken from the hands of amygdala- and hormonedominated drivers. In precisely the same way, the blessings that result from intelligent decision-making that has been freed from the dominance of human emotionality are predictable.

If that time should come, there will be sure benefits, among them: saving significant resources that used to be consecrated to electioneering; ending the political posturing of competing and fundamentally unqualified candidates; silencing the shouted avowals of candidates' promises later to be ignored, the screams of pat rhetoric, the exchange of juvenile insults, and the reduction in this heated, far from intelligent, and wholly inefficient process of selecting a country's leaders to a display of publicly supported inanity. All the while, it is a process that ultimately rests on an electoral majority who, on average, are at least as unqualified in knowledge and political acumen as the candidates themselves are. Government by artificial intelligence can replace the crowds of placard-bearing demonstrators, the shrilling pronouncements of the candidates, the heavy hands of special interest groups combined with the powerful sway of large corporations, and the unintelligence of the grand waste of time and money spent so that competing, largely uninformed human masses may cheer their respective candidates to 
victory. The prospect of leaving these things behind as vestiges of a more primitive level of human development should bring a sigh of relief!

Even so, government by artificial intelligence will itself present unanticipatable shortcomings in need of solution, a fact that is no persuasive reason against its gradual implementation; it will be a process no doubt marked by hesitancy, misgivings, and protest, false starts and mistakes. Government by AI is certainly not expected to come up all roses as artificial intelligence is gradually incorporated into actual governmental policy- and decision-making (it already plays major, firmly established, essential roles in governmental security, surveillance, cybersecurity, and the military). No path to human improvement is free from sometimes serious blunders and unforeseen dead ends. Notwithstanding the future evolution of artificial intelligence that will have to survive its own trials and errors, we need to appreciate that developments in artificial intelligence are taking place in a manner and on a level that is wholly alien to human beings, and in specific ways a vast improvement on them:

Earlier in this essay, we noted in passing that human development is perpetually impeded by the need to teach each new human generation, in endless repetition, much the same body of information and knowledge that has been learned by its predecessors. This always has been an obvious serious handicap to the pace of human evolution, a handicap that does not affect AI.

In addition, a related deficiency drags down human development: When a human car driver fails to look ahead before entering a freeway onramp in order to check whether an errant or mindless motorist may be speeding towards him or her going the wrong way, and a fatal crash results, this constitutes a human tragedyand one that nearly all other human drivers will fail to learn from. The interconnected computer system of autonomous vehicles, in contrast, can quickly profit from such one-time occurrences so that this information is automatically passed to all other autonomous vehicles, insuring that the same mistake does not happen again. The importance of this general ability of AI to learn quickly from 
past mistakes and automatically incorporate and update solutions to avoid them in the future cannot be underestimated, especially when we consider this ability in the context of government that is already increasingly managed by artificial intelligence.

Human history provides an ample record of several thousand years of avoidable suffering brought about by human cognitive and psychological shortcomings, century after century filled with bloody national implosions and international conflicts during which those very chronic human shortcomings have held people in a vicelike dominating death-grip. Human government by artificial intelligence-if human beings are sufficiently courageous, sufficiently self-aware, and wisely humble enough to face their own cognitive and psychological limitations-may offer a potential promising path for human development. Perhaps the only way humans can intelligently and effectively control themselves is to cede that control to technological means that human beings create to surpass themselves.

A second complementary path is also conceivable: By the time the human species reaches the stage, if it does, when its members self-consciously recognize the extent and seriousness of their own intrinsic human limitations of the kind outlined here, perhaps then deliberate constructive steps will begin to be taken to compensate for and remedy those limitations. Perhaps then, through purely human efforts, with no need to depend so heavily upon machines, people will begin to acquire an ability to govern themselves intelligently, reasonably, efficiently, and effectively, and then good and genuinely human self-government may become a possibility. 